\title{
THE STUDY OF DYNAMIC PROCESSES IN THE BOILER FURNACE WITH CIRCULATING FLUIDIZED BED
}

\author{
A. V. Gil ${ }^{1, *}$, and D. A. Baturin ${ }^{1}$ \\ ${ }^{1}$ National Research Tomsk Polytechnic University, 634050 Tomsk, Russia
}

\begin{abstract}
The paper presents a numerical simulation of the furnace with a circulating fluidized bed. Numerical study carried out on all volume of the combustion chamber. The results contours of particulate matter concentration and of velocities, as well as a graphical representation of changes in the concentration of particles on the bed height are shown. Simulation performed in Eulerian - Eulerian and Lagrange representation on a 3D model.
\end{abstract}

\section{Introduction}

Currently boilers with circulating fluidized bed (CFB) are widely used when low-quality coals are burnt. The quality of extracted coal with moisture and ash of more than $55 \%$ causes difficulty of incineration by the traditional flare way (the slagging of furnace screens, flameout, etc.). Combustion in circulating fluidized bed has high efficiency and allows to achieve low emissions of harmful substances by binding of sulfur oxides and lowtemperature combustion $[1,2]$.

However, this technology has several significant disadvantages associated with the mode of operation. Completeness of fuel combustion, the workload of the fluidized bed and gas-dynamic processes in the furnace are poorly understood, that lowers the reliability of boiler unit work (fig. 1) [2, 3].

The object of study is the U-shaped CFB boiler. The height of the furnace is $28 \mathrm{~m}$. The boiler has 4 burners on the front for the coal fuel supplying into the furnace, and 6 slits on the back side to return unburned particles. The particles that are leaving the furnace are separated into 2 streams and enter the cyclones for separation (fig. 1).

\section{Problem statement}

The main method to study gas-dynamic processes, heat transfer and high-speed modes is mathematical modeling. The obtained information can be applied in the design of thermal plants, as well as in the evaluation of already operated units.

For multiphase flow, computational fluid dynamic models have been become more accepted in modeling gas-solids flow systems during the recent years. There are two

* Corresponding author: andgil@tpu.ru 
approaches: Eulerian-Eulerian and Eulerian-Lagrangian models. In the Eulerian-Eulerian model, the solid phase is treated as a continuum, and an Eulerian framework is applied to describe the motion of the solids [4]. In most recent Eulerian-Eulerian model constitutive equations according to the kinetic theory of granular flow are incorporated [4-6]. Though physical characteristic of the solid particles such as the shape and size are included in the continuum representation through the empirical relations for the interfacial friction, these models do not recognize the discrete character of the solid phase [3].

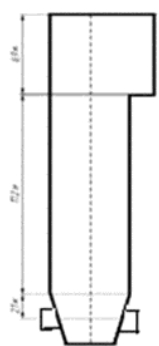

a)

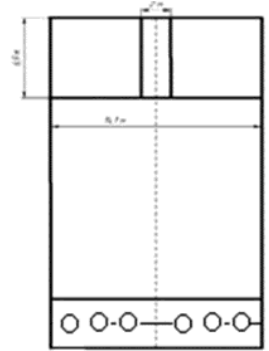

b)

Fig. 1. Sketch of the furnace: a) longitudinal section; b) cross section.

Baseline: project fuel - anthracite; fuel consumption $\mathrm{BP}=9.74 \mathrm{~kg} / \mathrm{s}$; the volume of primary and secondary air $5.79 / 1.07$; diameter of coal particles is $2.5 \mathrm{~mm}$; the temperature from below $600{ }^{\circ} \mathrm{C}$, in burners $300{ }^{\circ} \mathrm{C}$; the air velocity below $1.5 \mathrm{~m} / \mathrm{s}$.

\section{Mathematical model}

At present, there is no generally accepted mathematical model of the numerical analysis for the MSC and therefore, the simulation results using the two methods are present in the work. Euler - Euler Method allows to trace gas-dynamic process in the furnaces of CFB boilers, but does not allow to consider the movement of individual particles of the fuel [7, 8]. Lagrange-Euler approach allows to investigate a large number of individual dispersed particles, but not quite correctly reflected the processes in the lower furnace with circulating fluidized bed $[9,10]$.

The computational grid consists of 137673 of cells that contains 27749 knots and has 272690 separate surfaces. The number of structural elements is sufficient to conduct the study because it provides acceptable accuracy of calculation while maintaining high speed of its holding. The research was carry out by using ANSYS Fluent 12.1.4.

\section{Results and discussion}

Different approaches designed more than 3000 iterations. Fig. 2 shows the concentration of substances in the furnace volume obtained by modeling by Euler method modeling.

Figure 2 shows that in the lower part of the furnace, a layer of $1.5 \mathrm{~m}$ height is formed, where the concentration of fuel reaches the maximum value. Then, by supplying air from below the particles are distributed throughout the volume of the combustion chamber. In the near wall region, the concentration of fuel is higher than in the central part of the furnace. Air has opposite values with respect to the fuel. 


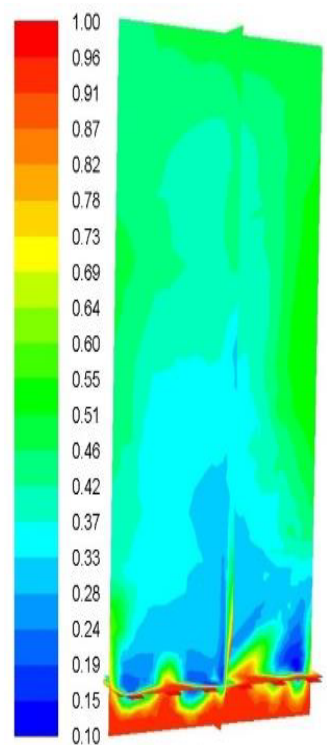

a)

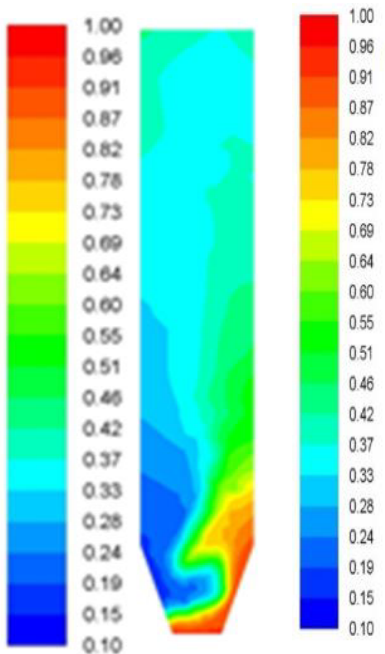

b)

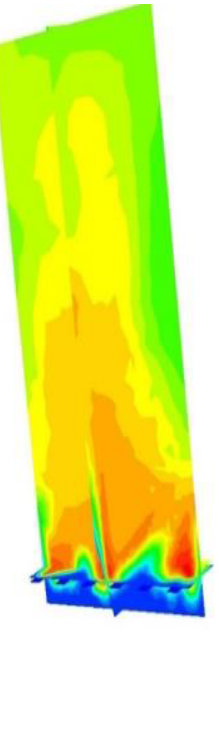

c)

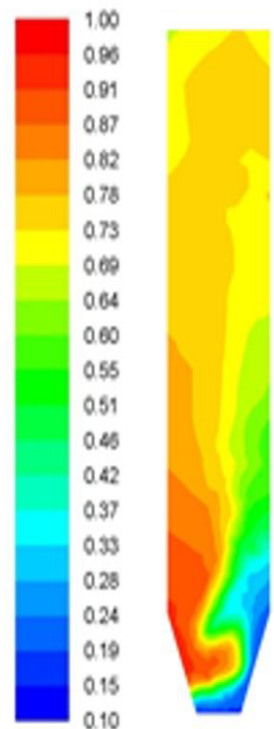

d)

Fig. 2. Concentration of the estimated phases at the height of the furnace in vertical sections: a) solid particles in the section along the transverse axis; b) solid particles in the cross section along the longitudinal axis; c) air in the section along the transverse axis; d) air in the cross section along the longitudinal axis.

Figure 3 shows differences of the speed limit depending on the modeling method.

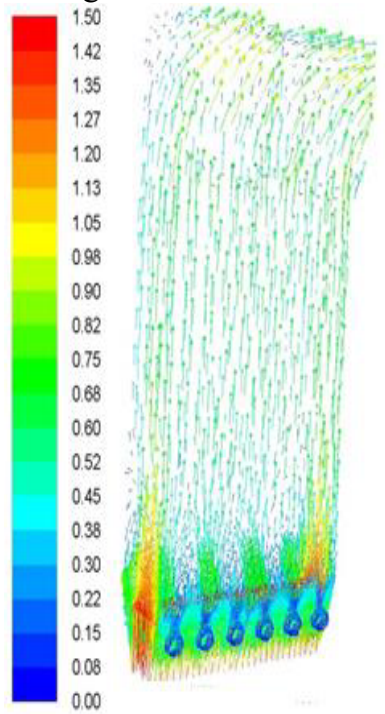

a)

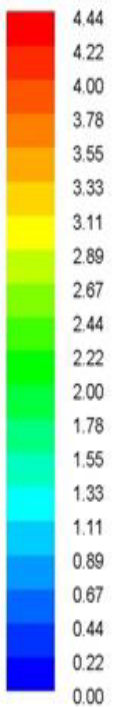

0.00

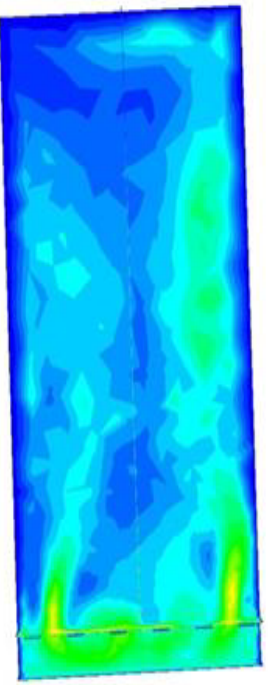

b)
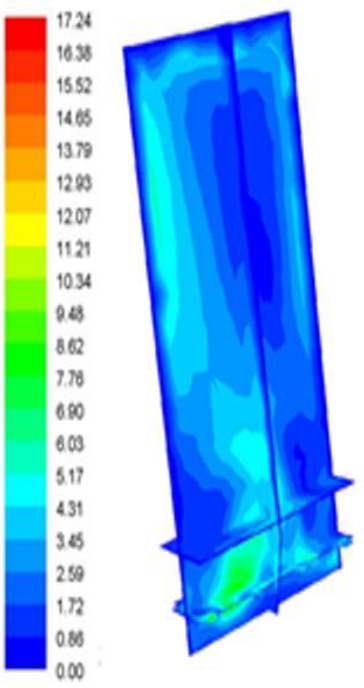

c)

Fig. 3. Speed (m/s): a) cold venting; b) the Eulerian-Eulerian model; c) the Eulerian-Lagrangian model.

In the cold blowing (fig. 3, a) the speed limit in the combustion chamber is observed, the maximum speed corresponds to the air supply from below at $1.5 \mathrm{~m} / \mathrm{s}$. At the exit of the furnace, average speed is $0.85 \mathrm{~m} / \mathrm{s}$. In the simulation by the Euler method (fig. 3, b) the average speed in the lower part of the furnace volume is $2.5 \mathrm{~m} / \mathrm{s}$. Then with the height of 
the furnace the average speed drops to $1.5 \mathrm{~m} / \mathrm{s}$. Average speed in the simulation by the Lagrange method (fig. 3, b) in the region of the burners is $5 \mathrm{~m} / \mathrm{s}$, and at the height of the furnace chamber is $2-3 \mathrm{~m} / \mathrm{s}$.

\section{Conclusions}

Simulation using Eulerian-Eulerian method allows to observe the fuel layer and the subsequent distribution of fuel particles along the height of furnace volume. It is not possible to achieve such situation by the method of Lagrange-Euler.

There is some deference in the speed limit in the lower and upper parts of the combustion chamber using different modeling approaches and remains in the range of optimal values for furnaces with circulating fluidized bed.

Using modeling approaches allows collectively to assess gas-dynamic processes and the operation of boilers with circulating boiling layer under the condition of a rational analysis of simulation results using different mathematical approaches. Accordingly, for a better assessment of results and forecasting of operating processes in the boiler furnace with circulating fluidized bed is necessary to develop a hybrid mathematical model for circulating fluidized bed boilers.

\section{References}

1. P. Basu, Combustion and gasification in fluidized beds (CRC Press, FL) (2006)

2. Nan Zhanga, Bona Lua, Wei Wanga, Jinghai Li, Chem. Eng. J. 162 (2010)

3. A.V. Gil, A.Y. Gil, Eur.Phys. J.Web Conf. 82, 01044 (2015)

4. Jun Xie, Wenqi Zhong, Baosheng Jin, Yingjuan Shao, Yaji Huang, Adv. Powder Technol. 24 (2013)

5. A.V. Gil, D. A., IOP Conf. Ser.: Mater. Sci. Eng. 93, 012003 (2015)

6. A.V. Gil, D. A. Baturin, MATEC Web Conf. 23, 01009 (2015)

7. Anusorn Chinsuwan, Animesh Dutta, Powder Technol. 193 (2009)

8. Mohammad Hadi Bordbar, Kari Myohanen, Timo Hyppanen Appl. Therm. Eng. 76 (2015)

9. G.A. Ryabov, O.M. Folomeev, D.A. Sankin, K.V. Khaneev, I.G. Bondarenko, D.A. Mel'nikov, Power Technology and Engineering 44 (2010)

10. A.V. Gil', A.S. Zavorin, A.V. Starchenko, S.V. Obukhov, Power Technology and Engineering 45 (2011) 